\title{
Hacia una nueva arquitectura jurídica
}

\author{
Carlos Raimundi | Universidad Nacional de La Plata
}

Revista Derechos en Acción / ISSN 2525-1678 / e-ISSN 2525-1686

Año 4/No 10 Verano 2018/2019 (21 diciembre a 21 marzo), 429-440

DOI: https://doi.org/10.24215/25251678e262

\section{Presentación}

El pasado 10 de diciembre se cumplieron 70 años de la redacción de la Declaración Universal de los Derechos Humanos, surgida de la flamante Organización de las Naciones Unidas para superar definitivamente las calamidades de la guerra que acababa de concluir.

A su vez, en la Argentina, en América Latina y en el mundo, atravesamos una etapa de injusticia y exclusión que pareciera dar por tierra con aquel propósito. Lo cual nos pone en la imperiosa necesidad de reparar los daños que ocasiona el neoliberalismo impuesto por el capital financiero globalizado, y recuperar una visión humanista y solidaria del mundo.

Por momentos parecería que estas políticas de sometimiento se apoyan sobre un laberinto jurídico que impide a los Pueblos una salida. Que, debido al enorme poder que las sostiene, resulta imposible liberarnos de esas barreras legales. Que no es viable edificar una nueva arquitectura normativa conforme a nuestros valores y principios igualitarios.

Pero no es así. La propia Declaración Universal de los Derechos Humanos establece con toda claridad la vigencia de los derechos de quienes padecen la pobreza, el hambre, la injusticia y el olvido, y que han sido quebrantados. Es decir, son los grandes conglomerados y su desenfreno para maximizar su ganancia financiera quienes han violado el derecho internacional y sometido a las grandes mayorias. Infringen todo principio 
de Justicia, Igualdad, Preservación del Medioambiente, Derecho al Trabajo, al Confort y a la Felicidad, al Buen Vivir en definitiva, que deberían ser condiciones elementales para la vida de todo Ser Humano. Para nosotros, la Política como valor, consiste precisamente en garantizar esos derechos, su ejercicio efectivo. Consiste en devolver la propiedad de los mismos a quien verdaderamente corresponde, la persona humana. Y a los Pueblos que están conformados por el conjunto de personas humanas.

\section{EI derecho internacional}

El artículo $1^{\circ}$ de la Declaración Universal consagra los principios de Libertad, Igualdad y Dignidad de todas las personas, los que se completan a lo largo de toda su extensión con el derecho de acceder a tribunales imparciales (art. 10), a la presunción de inocencia (art. 11) y a elegir libremente el Estado que será su residencia (art. 13), contraviniendo toda limitación a ejercer el derecho a emigrar. Además, a que se garantice un trabajo digno (art. 23) y un nivel de vida adecuado, expresado en un apropiado nivel de salud, educación gratuita, alimentación, vestido, vivienda y servicios sociales (art. 25).

Los art. 17 y 18 de la Carta establecen los derechos de propiedad individual y colectiva, y el compromiso de que nadie debe ser privado de los mismos, lo cual no debe restringirse a los bienes tangibles, sino extenderse a la apropiación de los bienes sociales como los mencionados, a los cuales podríamos agregar el esparcimiento o el acceso a los servicios públicos esenciales. En la medida que los intereses del mercado impidan el goce de los mismos, convertirá a este en una forma de totalitarismo, estará violando el derecho, y otorgando legitimidad a los Pueblos a implementar las vías que considere más propicias para su recuperación.

La Declaración Americana de los Derechos y Deberes del Hombre aprobada en Bogotá, 1948, reafirma esta doctrina, en coincidencia con los restantes Pactos Internacionales de Derechos Económicos, Sociales, Culturales, Civiles y Políticos, todos ellos 
ratificados, además, por el orden constitucional argentino, que les confiere una jerarquía superior a la de cualquier ley interna que los contradiga (art. 75 inc. 22 de la Constitución Nacional).

La evolución del sistema de poder a nivel mundial ha determinado que la violación de estos derechos no proviene tanto de los abusos provenientes del Estado, sino de la concentración del capital financiero trasnacional. Esto, no sólo impide a los Pueblos el goce de sus legítimos derechos, sino que inclusive somete a los Estados más débiles a través de la imposición de medidas restrictivas que derivan muchas veces de acuerdos internacionales de menor jerarquía ética y jurídica que los mencionados. Sin embargo, el art. 4 del Pacto Internacional de Derechos Civiles y su Protocolo Facultativo señala que un Estado está facultado para suspender sus obligaciones cuando esté en peligro la vida de la Nación, como ocurriría en caso de un endeudamiento excesivo que ponga en riesgo los derechos fundamentales de su población. Así como el interés de un monopolio u oligopolio privado que preste servicios esenciales de ningún modo puede prevalecer sobre el derecho bumano y social de una familia o un establecimiento fabril a acceder a los mismos, ningún acreedor puede colocar sus intereses financieros por sobre el interés supremo de un Pueblo a su preservación.

\section{El derecho interno}

En el derecho interno, es el Preámbulo de la Constitución Nacional el que ilumina desde el vértice de la pirámide jurídica a través de los grandes principios contenidos en él, a saber:

Constituir la Unión Nacional. Este principio ha sido reiteradamente trastocado por políticas que conllevaron y conllevan a una sociedad cada vez más fragmentada, no sólo desde el punto de vista de los ingresos materiales. El propósito de la fragmentación social se revela en la omnipresente intención de parte del poder real, de enemistar al Pueblo con la Política y con el Estado, como asimismo distanciar la consideración de los sectores medios hacia los sectores populares. 
"La política es corrupta" y "el Estado es ineficiente y anacrónico" son mensajes emitidos con absoluta persistencia desde todos los vectores de la comunicación en manos de los poderes establecidos, ya se trate de las noticias, la ficción o el humor, entre todos los demás campos de la comunicación y la cultura.

El otro mensaje pertinaz es aquel que da cuenta de logros como el trabajo y la vivienda por parte de sectores medios, como resultado del puro mérito individual, mientras que si los sectores más humildes no han podido acceder a ellos es por su falta de esfuerzo, y no debido a los límites estructurales que impone el modelo político y económico, intrínsecamente injusto.

Es posible que en algunos países centrales políticamente estables y socialmente cohesionados, los cambios de gobierno impliquen sólo una diferencia de matices en cuanto a las políticas centrales. En cambio, en países como el nuestro, que no han resuelto aún el dilema entre un proyecto de país soberano y un proyecto de colonia, cada cambio de gobierno suele expresar una suerte de cambio de régimen político. No hay margen para consensos fundamentales entre un jubilado y la administradora privada que arriesga sus haberes en la tómbola financiera, entre una familia rural y un pool de siembra preocupado por la cotización de la cosecha en un mercado asiático de futuro, ni entre una familia humilde y un monopolio que la priva de acceder a los servicios públicos esenciales. Esa "grieta" en torno de cuestiones fundamentales como la noción de Justicia, Libertad o Igualdad, es, por lo tanto, consecuencia de fórmulas neoliberales que han dividido deliberadamente a nuestras sociedades. Y esto es una clara violación del concepto de Unión Nacional postulado por el Preámbulo de nuestra Constitución.

El día que el Pueblo esté sólidamente asociado a la Política y al Estado, y los sectores medios y populares formen una abigarrada masa crítica en torno de sus demandas comunes, se habrá conformado entre ellos la gran coalición social y política capaz de detener la agresión de los proyectos oligárquicos, y se habrá configurado la necesaria "Unión Nacional" que proclama nuestra Constitución. 
Afianzar la Justicia. ¿Existe la Justicia en un país que tolera la prisión de personas sin condena firme o por razón de su pensamiento político? ¿Existe la Justicia cuando están detenidos quienes han cometido delitos leves como robar por hambre, mientras los funcionarios que causaron esa situación de inequidad colectiva y estructural no sólo están libres, sino que colocan sus fortunas colosales en guaridas fiscales del exterior? ¿Existe la Justicia en un país donde los jueces consienten el corte de un servicio esencial como la luz y el gas a una familia pobre por no pagar tarifas confiscatorias, mientras los balances de los monopolios prestadores arrojan ganancias siderales? En definitiva, es el modelo neoliberal el que vulnera el principio de Justicia contenido en el Preámbulo de la Constitución Nacional.

Consolidar la Paz Interior. En la medida en que la política estatal más se desentiende de la acción de los mercados, más deberá reforzar su faceta represiva para contener la demanda social. En cambio, si la política estatal disciplina a los mercados en pos de una mayor distribución del ingreso y la propiedad, menos deberá recurrir a sus atributos de coerción, consolidando, de ese modo, la Paz Interior. Esta es violentada, pues, por el modelo neoliberal, que actúa una vez más contrario a derecho.

Proveer a la Defensa Común. La defensa de la autonomía de un país va de la mano del desarrollo de la educación, la ciencia y la tecnología. Los recortes presupuestarios que cercenan esos derechos a una porción cada vez mayor de la población van en sentido contrario del principio de la Defensa Común, aun si se lo pretendiese limitar al terreno de la defensa militar. Nuevamente es el neoliberalismo, y no los proyectos nacionales $\mathrm{y}$ populares, los que no proceden conforme a derecho.

Promover el Bienestar General. ¿Cómo asociar el Bienestar General con los despidos, recortes a la inversión estatal en bienes sociales, cierres de fábricas y talleres? El proyecto neoliberal (que es a su vez neo-colonial y neo-fascista) encubre debajo de sus frases más grandilocuentes como "volver al mundo", "obtener una lluvia de inversiones" o "favorecer un clima de negocios", su verdadero objetivo que es bajar el salario, mediante la amenaza 
extorsiva de que de otro modo se perderá el empleo. El cierre de fuentes de trabajo y los bajos salarios no sólo gravitan en la economía de una familia, sino que la retrotraen a encrucijadas primitivas como mitigar el hambre y preservar el lugar en la fábrica. De este modo, abocada a la resolución de esas necesidades básicas, la familia se aparta de considerar otros temas fundamentales para el bienestar de un país como la propiedad soberana de sus tierras y sus recursos naturales estratégicos, que se tornan abstractos en comparación con aquellas necesidades acuciantes, las cuales, durante los gobiernos populares se dan por superadas.

Asegurar los beneficios de la Libertad. ¿Cómo asegurar libertades enunciadas en nuestro cuerpo normativo como la de entrar y salir del país o la de acceder a la Universidad pública de manera irrestricta, al niño que mendiga bajo el semáforo de la una esquina?

Somos herederos de los principios políticos de la revolución francesa, Libertad, Igualdad, Fraternidad. Pero los dos últimos tienen alcance sólo retórico respecto del primero, que se torna sustantivo por estar asociado a los principios económicos del Laissez faire-laissez passer (libertad de industria, libertad de comercio). Para aquella burguesía en ascenso, el papel del Estado y su relación con el valor Libertad tenía que ver con la defensa de la libertad económica y la propiedad privada individual, mucho más que con garantizar la dignidad de la persona y la propiedad de los derechos sociales. En nombre de aquella concepción de la Libertad, el capitalismo sobreviniente cometió los más terribles abusos. Para nosotros, en cambio, cuando la libertad oprime, el Estado libera. El derecho es la forma jurídica de un proyecto politico. Para liberar a los pueblos concebimos al derecho $y$ al Estado.

Para nosotros, para nuestra posteridad, y para todos los hombres del mundo que quieran habitar en el suelo argentino, lo cual desmiente por sí mismo toda posibilidad de poner límites a la presencia de hermanas y hermanos latinoamericanos en nuestro territorio. No son ellas ni ellos, sino la pésima administración política y económica del neoliberalismo-neoco- 
lonialismo-neofascismo, el responsable de la falta de trabajo y la pobreza de estos momentos.

Por último, mientras la disposición transitoria primera de nuestra Constitución Nacional ratifica nuestra soberanía imprescriptible e irrenunciable sobre las Islas Malvinas, Georgias $y$ Sandwich del Sur y los espacios maritimos e insulares correspondientes, la administración neoliberal de Mauricio Macri ha claudicado invariablemente respecto de dicho postulado.

\section{Descolonizar el saber. Disputar y reconquistar el sentido común}

La pregunta que surge, luego de analizar los grandes lineamientos del sistema jurídico tanto internacional como interno, es por qué partiendo de dichos principios hemos llegado a estos resultados. Y por qué creemos que tanto el derecho internacional como el derecho interno pueden llegar a ser un límite para nuestras aspiraciones de desendeudamiento, desmonopolización, intervención del Estado sobre el sector financiero, las corporaciones que manejan la tecnología agropecuaria, el comercio exterior, la circulación de divisas o las empresas que prestan servicios esenciales.

Por el contrario, es el totalitarismo del capital financiero globalizado el que ha transitado por la ilicitud y la apropiación indebida de derechos (y por qué no el delito), el que ha procedido de manera contraria al derecho, lo ba violentado y ba tergiversado el significado del derecho, cuya naturaleza es ser un instrumento de la Justicia y la Igualdad en su sentido más profundo, y no de los privilegios de una élite.

¿Cómo es posible que a partir de principios generales creados para amparar la Justicia, la Igualdad y el Bienestar General se haya llegado a resultados tan antagónicos, en términos de injusticia, desigualdad, desamparo, malestar? ¿Cómo puede ser que el poder haya construido normas jurídicas, éticas y lógicas para resguardar valores y situaciones antitéticas respecto de lo que los principios del derecho proclaman? 
Boaventura de Souza Santos hace, junto a José Mariátegui, Enrique Dussel, Walter Mignolo, Aníbal Quijano y otrxs autorxs, un aporte más que importante a la descolonización de la cultura, el lenguaje, el saber y las estructuras de poder, a partir de lo que considera una nueva epistemología, la "Epistemología del Sur", una mirada desde las luchas, no desde el poder.

En ese sentido, proponemos la elaboración de un nuevo paradigma jurídico. La presente judicatura aparentemente republicana se asienta en realidad sobre principios monárquicos, como el ser impartida desde "el palacio", ser vitalicia, hereditaria, y estar eximida de pagar impuestos. Cuando el impartir justicia, tal como sucede con la economía, pasa a ser un saber de expertos, elaborado en un laboratorio y expresado en un lenguaje críptico, se aparta de toda connotación social, de toda aspiración a resguardar la paz y los derechos de las mayorías, para convertirse en un reducto de las élites del poder económico y tecno-burocrático, con la única finalidad de ayudarlas a mantener sus privilegios.

La consigna es, pues, democratizar la Justicia. Recuperar al Derecho como herramienta de la Democracia, no de la explotación. En este proceso de giro des-colonial, es necesario poner en disputa el sentido común configurado por los poderes fácticos en todos los terrenos.

En el plano internacional, digamos que los principales rasgos que definen al terrorismo son la muerte de inocentes, el tráfico de armas, la ruptura de las democracias. ¿Cuál es el país que ostenta en su haber el mayor número de víctimas inocentes, que más armas comercia y utiliza y que más democracias ha destruido? ¿Cuál es, en suma, el Estado que despliega más prácticas propias del terrorismo, aunque en la retórica pregone su intención de combatirlo?

En el terreno de las grandes cadenas de medios hegemónicos, digamos que la información, la comunicación, la cultura y el entretenimiento son derechos públicos. $\mathrm{Y}$ el espacio por donde transitan dichos contenidos, sea éste físico o virtual, analógico 
o digital, por cable, fibra óptica, satélite o como fuere, es un espacio público. ¿Cómo puede ser, entonces, que la renta generada por el ejercicio de un derecho público que se transmite a través de un espacio público sea capturada por los monopolios mediáticos en lugar de ser socialmente distribuida?

En el terreno de los recursos estratégicos, que son de pertenencia pública, ¿cómo puede ser que su renta sea aprehendida por las multinacionales de la tecnología del petróleo, los cultivos, los alimentos o los medicamentos, en lugar de ser distribuida socialmente?

En el terreno financiero, ¿de quién son los recursos de los bancos, sino de sus aportantes, es decir, del Pueblo? ¿Por qué, entonces, están los Pueblos tan pobres y los banqueros tan ricos, si la tarea de estos últimos es simplemente administrar recursos que no les son propios?

Si una política de salud es administrada por un laboratorio privado en lugar del Estado, este necesitará convertir la enfermedad en crónica, para que sus negocios se sostengan indefinidamente en el tiempo. Si el petróleo es administrado por una corporación en lugar del Estado, la necesidad de maximizar y reproducir la ganancia la obligará a girar sus utilidades hacia nuevos mercados en lugar de reinvertirlas en favor del país que acredite la propiedad social del recurso. ¿Cómo se explica la existencia de Estados fuertemente dotados de recursos naturales, cuyos pueblos viven no obstante sumidos en la pobreza y el subdesarrollo?

La respuesta a estos interrogantes la encontramos en la necesidad de desestructurar el pensamiento colonial en el que fuimos formados. En nuestras escuelas debemos "desaprender" los preconceptos y estereotipos diseñados con inteligencia por el poder monopólico del capital financiero trasnacional para preservar su posición dominante. Al cabo de ese proceso, a nadie le quedaría la duda de que el Derecho y los sistemas jurídicos no pueden ser un instrumento de las prerrogativas de una minoría de poder, sino una herramienta de la Democracia profunda, aquella que se asienta en el poder popular. 


\section{Conclusión}

El desamparo de un ser humano -más aun de millones de ciudadanas y ciudadanos- jamás podría ser tolerado por quienes profesamos la política desde una concepción humanista. Pagar el precio del desamparo a raíz de razones o explicaciones económicas implica para nosotros un trastocamiento de valores tan fundamental, que nos aleja irremediable e innegociablemente de quienes lo hacen. Somos portadores de otro modelo.

La maquinaria de subjetividad colonial interviene sobre los elementos de la relación comunicativa, disolviendo la identidad y la historia de una manera totalmente postmoderna. Intenta crear un sujeto fragmentado. Al asociar capitalismo con libertad o democracia, bajo un supuesto pluralismo adoctrina en el pensamiento único. Al presentarse como un servicio que basa su prestigio en la credibilidad del mensaje, los medios aprovechan para jerarquizar lo novedoso frente a lo importante, lo espectacular frente a lo sustantivo. Así, intentan incapacitar a la sociedad para ser consciente de las consecuencias del modelo de dominación y buscan instalar que su esfuerzo y toda construcción política será inútil para cambiar las cosas.

El dinero virtual se mueve a la velocidad de nanosegundos. Un poder galopante llegó para destruir todos los lazos y priorizar el deseo de lo efímero, anclar la subjetividad sólo en la inmediatez. Se desplaza toda posibilidad de construir lazos colectivos, ni a partir de la historia común, ni de la esperanza. Se intenta construir una apariencia de libertad centrada en la posibilidad de elegir los objetos de consumo, cuando en realidad, paradójicamente, estamos en presencia de la influencia ideológica y el control más desmedido que conozcamos.

El desafío es, en definitiva, delinear nuevos paradigmas de felicidad. Pier Paolo Pasolini pensaba el conflicto político -esto es, la búsqueda de la libertad- como una disputa entre diferentes ideas de felicidad. Veía como imposible el proponer otras finalidades dentro del actual marco de acumulación, para concluir en que "son necesarios otros vestires y otros andares, otra 
seriedad y otras sonrisas, otros comportamientos". La disputa política expresa un desacuerdo ético entre diferentes ideas de la vida, (de la "buena vida" según Pasolini, del "buen vivir" de los pueblos originarios), ideas que se inscriben en los gestos y en los dispositivos más cotidianos. Ideas distintas de las de la eficiencia y el productivismo en las que se cimenta el capitalismo. Sólo un nuevo imaginario, una nueva subjetividad, una nueva organización del deseo tendrán la fuerza para quebrar y superar la insatisfacción vigente, según la cual la riqueza se asocia con el vivir para trabajar, en lugar de trabajar para gozar de la vida.

En la Argentina aún está en disputa la disyuntiva entre Patria o colonia. Hasta tanto no esté resuelta en favor de la Patria, el derecho está en disputa, el lenguaje está en disputa, la formación del sentido está en disputa. Cómo se interprete una misma palabra, un principio o una norma jurídica, dependerá de quién los designe

En este marco, de lo que se trata es de construir un nuevo paradigma jurídico, un nuevo modo de interpretación del derecho, de los intereses a tutelar por él, que vaya en la dirección enunciada. El derecho es el esquema normativo de una serie de objetivos políticos; es la forma jurídica de un proyecto político. Una vez definido ese proyecto, sus prioridades, sus finalidades, y a partir de los principios generales enunciados, se diseña la estructura jurídica que dará legalidad formal a esos contenidos. El derecho colabora con la política, no a la inversa.

De ese modo se procedió cuando se lideró la doctrina de los crímenes de lesa humanidad, cuando se restructuró la deuda privada, cuando se rechazó el proyecto del ALCA, cuando se recuperaron los fondos previsionales del ANSES, cuando se recuperó AySA, Aerolíneas Argentinas e YPF, cuando se puso límites a la propiedad de tierras en manos extranjeras o cuando se rechazó el fallo del juez Griesa y se propuso una doctrina internacional para limitar las consecuencias sociales del endeudamiento de Estados soberanos que se plasmó en 9 principios aprobados por las Naciones Unidas. 
La política es mucho más que "el arte de lo posible". Es cierto que debe partirse de un principio de realidad, de premisas verdaderas y no idílicas. Pero si la política sólo actuara dentro de los límites que le impone "lo posible", perdería toda su esencia transformadora, que es el fuego sagrado que la sostiene.

La voluntad, la decisión, el coraje, son rasgos esenciales de la política. Combinando base social, liderazgo, unidad de concepción, programa y organización, la política debe proponerse "generar acontecimiento", esto es, crear las condiciones que hagan posibles los objetivos políticos propuestos. Sin perder de vista aquello de lo que el capital trasnacional carece: ética y dimensión humana. 